\title{
EVALUATION OF MOST COMMON SYMPTOMS AND FINDINGS \\ IN TURKISH ADOLESCENT GIRLS WITH POLYCYSTIC OVARY SYNDROME
}

\section{Mina Gulfem KAYA ${ }^{1}$, Cevdet AYDIN², Sefika Burcak POLAT ${ }^{1}$, Duriye Deniz DEMIRSEREN, Reyhan ERSOY², Bekir CAKIR ${ }^{2}$}

${ }^{1}$ Ataturk Education and Research Hospital, Department of Endocrinology and Metabolism, Ankara, TURKEY ${ }^{2}$ Yıldırım Beyazit University Faculty of Medicine, Department of Endocrinology and Metabolism, Ankara, TURKEY ${ }^{3}$ Ataturk Education and Research Hospital, Department of Dermatology, Ankara, TURKEY

\section{OBJECTIVE}

$>$ Polycystic ovary syndrome (PCOS) is a complex endocrinopathy affecting $5-10 \%$ of women in reproductive period. Our goal is to determine which symptoms and findings are the most common in Turkish adolescents with PCOS.

\section{MATERIAL AND METHOD}

$>$ Ninety three adolescents (15-19 years old) who admitted to our outpatient clinic with at least one of the complaints (acne, obesity, menstrual irregularities and hirsutism) were enrolled in the study. All patients were evaluated due to both Rotterdam and $\mathrm{NIH}$ criteria.

\section{RESULTS}

$>$ Due to Rotterdam and $\mathrm{NIH}$ criteria 40 (43.01\%) and 32 $(34.40 \%)$ of patients were diagnosed as PCOS respectively. Due to Rotterdam menstrual irregularities were $90 \%$, hirsutism was $45 \%$, obesity was $25 \%$ and acne was $32.5 \%$ in patients diagnosed as PCOS. Due to $\mathrm{NIH}$ these ratios were $96.9 \%$, $50 \%, 25 \%$ and $31.3 \%$ respectively (Figure 1 ). Patients were divided into 12 subgroups due to combinations of complaints. Due to Rotterdam, PCOS diagnosis were $100 \%$ for menstrual irregularities and hirsutism together, $75 \%$ for menstrual irregularities and acne together, $66.7 \%$ for menstrual irregularities and obesity together, $66.7 \%$ for only hirsutism, $50 \%$ for hirsutism and acne together, $40 \%$ for only menstrual irregularities, $3.7 \%$ for only acne and $0 \%$ for only obesity. Due to $\mathrm{NIH}, \mathrm{PCOS}$ diagnosis were $100 \%$ for menstrual irregularities and hirsutism together, $66.7 \%$ for menstrual irregularities and acne together, $44.4 \%$ for menstrual irregularities and obesity together, $33.3 \%$ for only hirsutism, $26.7 \%$ for only menstrual irregularities, $0 \%$ for only acne or only obesity. Eight patients were diagnosed as PCOS only due to Rotterdam.

\section{CONCLUSION}

$>$ The most common complaints in Turkish adolescents with PCOS were menstrual irregularities, hirsutism, acne and obesity in our study. According to guidelines PCOS in adolescents is based on clinical and/or laboratory hyperandrogenism together with persistent oligomenorrhea. Polycystic ovarian morphology can be a part of reproductive changes in adolescents.

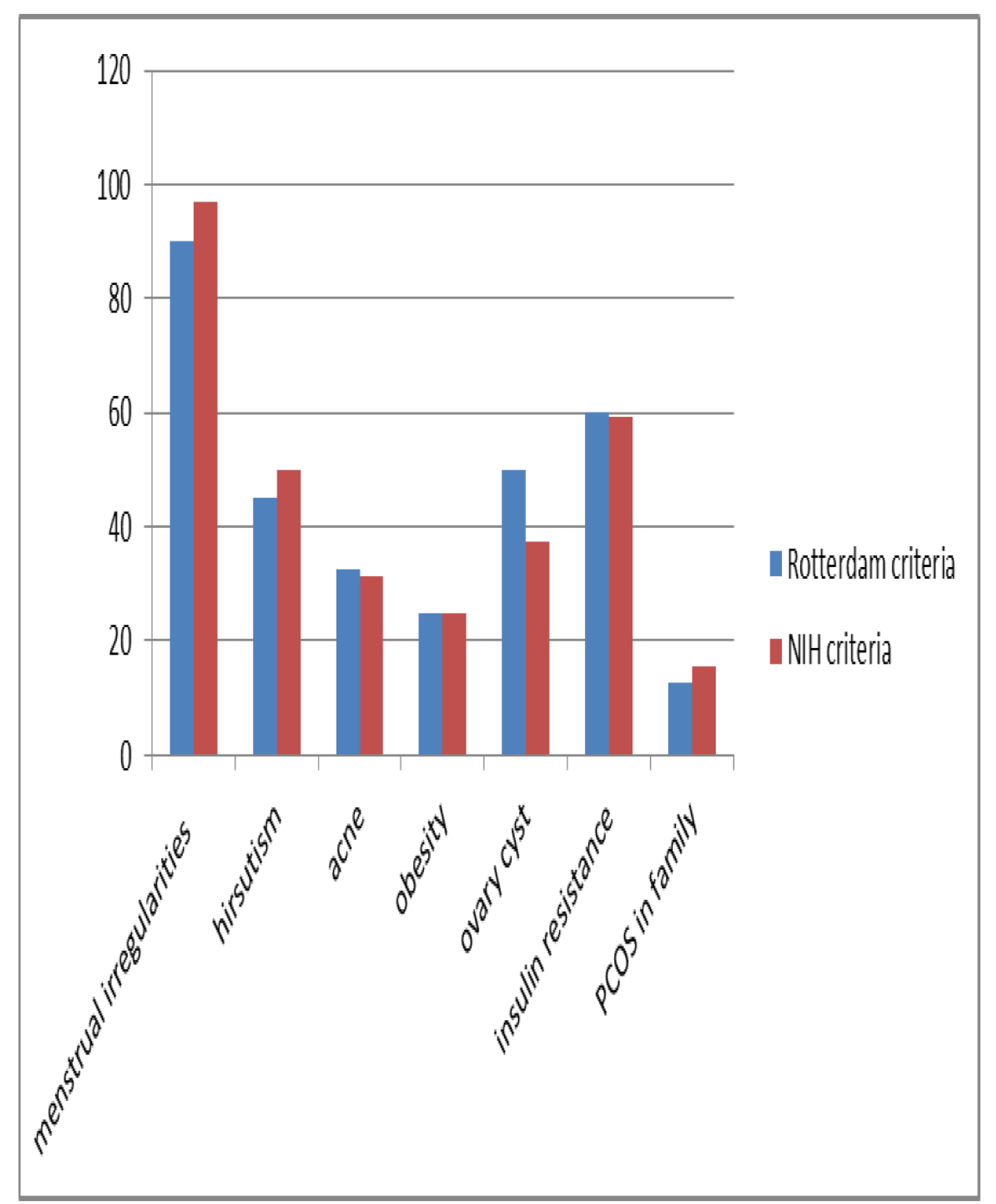

Figure 1: Percentage of patients' findings who diagnosed as PCOS due to Rotterdam and NIH criteria 